\title{
Desastres ecológicos e a saúde: plêiade de ampla magnitude e baixa percepção
}

Ecological disasters and health: pleiad of wide magnitude and low perception

Desastres ecológicos y salud: pléyade de gran magnitud y baja percepción

Marcia Chame ${ }^{1}$

Luciana Sianto ${ }^{2}$

\section{Resumo}

CHAME, M.; SIANTO, L. Desastres ecológicos e a saúde: plêiade de ampla magnitude e baixa percepção. Rev. C\&Trópico, v. 45, n. 2, p. 23-35, 2021. DOI: https:// doi. org/10.33148/cetropicov45n2(2021)art2

Desastres são eventos de alto impacto de origens distintas e determinados no tempo e no espaço. Nos últimos anos, os desastres vêm aumentando em frequência e intensidade em razão das alterações climáticas, desmatamentos, urbanização, adensamento populacional, ocupação irregular do solo, entre outros fatores, resultando em mortes e em prejuízos financeiros. Os desastres ambientais integram e acumulam diversas classes de desastres, o que eleva a complexidade de sua gestão. Os desastres ecológicos retroalimentam e magnificam desastres ambientais e podem levar ao rompimento da capacidade de manutenção dos ciclos biológicos vitais, ao colapso dos serviços ambientais com severas implicações no estresse fisiológico dos indivíduos e comunidades, não só humana, e à perda da biodiversidade. O potencial dos desastres ecológicos de provocar ameaças de magnitude incalculável e não previsíveis, como as pandemias, aumentam a vulnerabilidade de países, populações e pessoas mais pobres. Tratar a emergência de zoonoses como consequência de desastres ecológicos possibilitaria fortalecer a integração entre ferramentas tecnológicas, como o Sistema de Informação em Saúde Silvestre SISS-Geo (Fiocruz), ações da gestão de desastres e a vigilância em saúde com o monitoramento da biodiversidade. Além do mais, ações conjuntas, integradas e participativas são oportunas para o avanço na percepção e conscientização dos riscos destas emergências nas sociedades, empresas e especialmente nos governos.

Palavras-chave: Zoonoses. Emergência de doenças. Colapso ecológico. Patógenos. Biodiversidade.

1 DSc. em Zoologia, Universidade Federal do Rio de Janeiro, Coordenadora da Plataforma Institucional Biodiversidade e Saúde Silvestre, Fundação Oswaldo Cruz, Rio de Janeiro, RJ. Email: marcia.chame@ fiocruz.br ORCID: https://orcid.org/0000-0003-4680-500X.

2 DSc. em Saúde Pública, Fundação Oswaldo Cruz, atualmente bolsista da Plataforma Institucional Biodiversidade e Saúde Silvestre, Fundação Oswaldo Cruz, Rio de Janeiro, RJ. Email: lucianasianto@gmail. com. Orcid: https://orcid.org/0000-0003-3511-350X 


\section{Abstract}

CHAME, M.; SIANTO, L. Ecological disasters and health: pleiad of wide magnitude and low perception. Rev. CઐTrópico, v. 45, n. 2, p. 23-35, 2021. DOI: https://doi.org/10.33148/ cetropicov45n2(2021)art2

Disasters are high-impact events with distinct origins and determined in time and space. In recent years, disasters have increased in frequency and intensity due to climate change, deforestation, urbanization, population density, irregular land use, among other factors, resulting in deaths and financial losses. Environmental disasters integrate and accumulate different classes of disasters, which increases the complexity of their management. Ecological disasters feedback and magnify environmental disasters and can lead to disruption of the capacity to maintain vital biological cycles, the collapse of environmental services with severe implications for the physiological stress of individuals and communities, not just humans, and the loss of biodiversity. The potential of ecological disasters to provoke threats of incalculable magnitude and unpredictable, such as pandemics, increase the vulnerability of the poorest countries, populations, and people. Treating the emergence of zoonoses as a consequence of ecological disasters would make it possible to strengthen the integration between technological tools, such as the Wildlife Health Information System - SISS-Geo (Fiocruz), disaster management actions and health surveillance with monitoring of biodiversity. Furthermore, joint, integrated, and participatory actions are opportune to advance the perception and awareness of the risk of these emergencies in society, companies and, especially, in governments.

Keywords: Zoonoses. Disease emergence. Ecological collapse. Pathogens. Biodiversity.

\section{Resumen}

CHAME, M.; SIANTO, L. Desastres ecológicos y salud: pléyade de gran magnitud y baja percepción. Rev. C\&Trópico, v. 45, n. 2, p. 23-35, 2021. DOI: https://doi.org/10.33148/ cetropicov45n2(2021)art2

Los desastres son eventos de alto impacto con diferentes orígenes, determinados en el tiempo y el espacio. En los últimos años, los desastres han aumentado en frecuencia e intensidad debido al cambio climático, la deforestación, la urbanización, la densidad de población, el uso irregular de la tierra, entre otros factores, resultando en muertes y pérdidas económicas. Los desastres ambientales integran y acumulan diferentes clases, lo que aumenta la complejidad de su manejo. Los desastres ecológicos retroalimentan y amplifican los desastres ambientales, alterando potencialmente la capacidad de mantener ciclos biológicos vitales, colapsando los servicios ambientales, con serias implicaciones para el estrés fisiológico de individuos y comunidades, y la consecuente pérdida de biodiversidad. El potencial de las catástrofes ecológicas para provocar amenazas de magnitud incalculable e impredecible, como las pandemias, aumentan la vulnerabilidad de los países, las poblaciones y 
las personas más pobres. El tratamiento de la emergencia de zoonosis como consecuencia de desastres ecológicos permitiría fortalecer la integración entre herramientas tecnológicas, como el Sistema de Información de Salud de Vida Silvestre - SISS-Geo (Fiocruz), acciones de manejo de desastres y vigilancia de la salud con monitoreo de la biodiversidad. Además, las acciones conjuntas, integradas y participativas son oportunas para avanzar en la percepción y conciencia del riesgo de estas emergencias en la sociedad, las empresas y, especialmente, en los gobiernos.

Palabras Clave: Zoonosis. Emergencia de enfermedades. Colapso ecológico. Patógenos. Biodiversidad

\section{Contexto}

Desastres são eventos de alto impacto, de origens distintas, consequentes ou não da ação humana e determinados no tempo e no espaço. Nos últimos anos, dados publicados apontaram para o aumento na frequência e intensidade dos desastres associados a alterações climáticas (IPCC, 2021), desmatamentos, urbanização, adensamento populacional, ocupação irregular do solo, entre outros fatores (PAUL, 2020), resultando em perda de vidas e em gastos financeiros (CORONESE et al., 2019).

De acordo com sua origem, o Sistema Nacional de Proteção e Defesa Civil do Brasil os classifica em: tecnológicos (Radiativos, Produtos Perigosos, Incêndios Urbanos, Obras Civis, Transporte de Pessoas e Cargas), naturais (Geológico, Hidrológico, Meteorológico, Climatológico e Biológico) e (Codificação Brasileira de Desastres - COBRADE). Quando ocorrem, mobilizam diversos setores da sociedade e governos e volumosos recursos financeiros para atendimento pontual da emergência, ações de rescaldo, além das consequências da perda de vidas, indenizações, impactos e alterações nas atividades econômicas e sociais que podem se manter por longos períodos e de modo irreversível. Na maioria das vezes, e prioritariamente, os governos focam a atenção nas ações da resposta pós desastres e recuperação e não na prevenção, mitigação e preparação para tais eventos. Em todo o mundo, as perdas econômicas, sociais e ambientais determinadas pelos desastres impulsionam centros de estudos dedicados e a estruturação de planos e programas para a sua gestão ${ }^{3}$.

A avaliação de risco é um dos principais instrumentos da gestão para a prevenção de desastres uma vez que estes podem ser sazonais, súbitos ou graduais, com evolução crônica e, neste caso, de avanço pouco perceptível ou subestimado. A periodicidade e intensidade também são fatores de avaliação importantes, pois podem culminar na calamidade pública. Assim, a avaliação de risco pressupõe a identificação e caracterização das ameaças, a avaliação e hierarquização dos riscos, que são ponderados com a vulnerabilidade física, econômica, ambiental, social e, claro, com a probabilidade de sua ocorrência e capacidade de impedi-los ou controlar seus impactos.

3 https://www.gov.br/pt-br/categorias/forcas-armadas-e-defesa-civil 
Embora a Estratégia Internacional para a Redução de Desastres (EIRD $\left.{ }^{4}\right)$ traga conceitualmente a intenção de controlar completamente os danos provocados pelos desastres, no Brasil os esforços para a mitigação tem sido o caminho mais profícuo, incluindo a integração entre diferentes níveis e setores governamentais e da sociedade, processos participativos que contam com ações educativas para a percepção, a conscientização e a convivência com o risco (MACIEL et al. 2021). No universo da gestão de desastres se desenvolvem planos de ação, capacitação de pessoal, define-se critérios de avaliação e monitoramento, protocolos e planos de contingência de verificação continuada, idealmente testados.

Quando os desastres são ambientais ${ }^{5}$, naturais ou tecnológicos, integram, sobrepõem e acumulam consequências de diversas classes de desastres, o que eleva a complexidade da avaliação de risco. Os planos de contingência, controle e prevenção passam, portanto, a tratar concomitantemente com efeitos e danos de múltiplas ordens, que somados ou combinados entre si podem determinar novos desastres, muitas vezes imprevisíveis e de baixa percepção social e interesse governamental.

Embora por vezes tratados como sinônimos, os desastres ambientais potencialmente se transformam em desastres ecológicos, quando seus efeitos se propagam e podem levar ao rompimento da capacidade de manutenção dos ciclos biológicos vitais, ao colapso dos serviços ambientais, com severas implicações no estresse fisiológico dos indivíduos e comunidades, não só humana, levando à perda da biodiversidade, que em última instância provém a vida (UNISDR, 2015).

Os desastres ecológicos diferem dos desastres ambientais, pois ainda que não tenha ocorrido necessariamente qualquer desastre natural ou tecnológico pontual e de grande vulto, eles podem ser cumulativamente determinados e impulsionados pelas atividades humanas cotidianas, especialmente o comportamento e hábitos generalista, gregário, migratório e predatório (GLADWELL, 2000). Naturalmente existentes em intervalos de tempo largos, muitas vezes de milhares de anos, o que permite que os ecossistemas se reestruturem, os impactos antrópicos são cada vez mais frequentes, intensos e extensos, extinguindo espécies, favorecendo outras e muitas vezes nenhuma. Neste sentido, pode-se considerar que os desastres ecológicos são aqueles que retroalimentam e magnificam desastres ambientais, como bolas de neve, gerando simplificação das comunidades biológicas e fragilizando suas redes de sustentabilidade (polinização, banco de sementes, perda de predadores de topo, invasão de espécies exóticas, patogênicas e pragas, dentre outros elementos). Com potencial de provocar ameaças de magnitude incalculável e não previsíveis, como as pandemias, esses desastres demandam ações de remediação ou mitigação muitas vezes desconhecidas e custosas, aumentando a vulnerabilidade de países, populações e pessoas mais pobres. Os governos, empresas e a sociedade assumem pela negligência, incapacidade ou interesses particulares as consequências que geram fome, insegurança alimentar, escassez de água, doenças, migrações, violência, perdas econômicas e de qualidade de vida de todas as espécies.

4 https://brasil.un.org/pt-br/95681-estrategias-nacionais-e-locais-para-reducao-do-risco-de-desastres-sao-tema-de-dia

5 https://www.treehugger.com/americas-worst-man-made-environmental-disasters-4869316 
Em razão da alta capacidade de redundância, resistência e resiliência dos ecossistemas, os desastres ecológicos só são percebidos pelos humanos quando colapsam ou ameaçam os serviços ambientais dos quais as pessoas dependem. Entre os muitos exemplos facilmente encontrados na literatura estão os impactos antrópicos, que contribuem para o desastre ecológico, que é o esgotamento e alteração da dinâmica dos ecossistemas dulcícolas. Não há na sociedade percepção clara das múltiplas origens do problema, tão pouco vontade política de impedir o avanço desses impactos. Assim, as soluções para conter o déficit hídrico e a potabilidade da água doce, consequência direta do desmatamento generalizado, represamentos, aumento da temperatura global e local, usurpação das matas ciliares e nascentes, uso irracional para o agronegócio, mineração, lançamento de esgotos domésticos e industriais, eutrofização por aporte de insumos agrícolas, assoreamento e outros fatores, baseiam-se na captação de água de bacias vizinhas, transposições, uso descontrolado de aquíferos, construções de mais barragens e outras práticas pouco sustentáveis. Aos que não migram para áreas favoráveis, resta a morte ou a miséria. Como elemento central à vida, é imediato o entendimento da obrigatoriedade da restauração de florestas, proteção das nascentes, chapadas e conservação de áreas naturais de grande área, além da consciência e esforços para que toda a água nasça e chegue ao mar limpa.

Estão nos desastres ecológicos os riscos e impactos à saúde, tratados obviamente e quase que exclusivamente sobre o ponto de vista da saúde humana e assistencialista, ainda limitado na perspectiva dos programas de Saúde Única, Planetária ou Global.

Embora os riscos biológicos englobem as epidemias provocadas por agentes infecciosos virais, bacterianos, fúngicos e por outras espécies parasitas, além das pragas e infestações, as ações de mitigação e controle na saúde e na agropecuária apostam mais na eficácia do uso químico, medicamentoso e farmacológico, mais caro e menos democrático do que na prevenção, mais barata e com ganhos humanitários.

Na literatura especializada, são inúmeros os exemplos de doenças infecciosas consequentes de desastres naturais, embora estes não sejam assim classificados (HULLAND et al, 2019; PAUL, 2020). A pandemia de COVID-19, por exemplo, poderia ser classificada como um desastre ecológico, uma vez que inicia com o contato naturalmente improvável entre espécies de hospedeiros (animais silvestres - humanos) (“spillover”); o vírus avança sobre a população do novo hospedeiro pela sua plasticidade gênica, que lhe confere alta capacidade de transmissão e infecção; se dispersa pelo planeta favorecido pelo comportamento humano; e pela sua plasticidade e alcance geográfico impõe risco de transmissão reversa ("spillback") a outras espécies de animais silvestres e domésticos (KREUDER JOHNSON et al. 2015; DI GUARDO, 2021). Os danos são catastróficos ${ }^{6}$ (DOBSON et al, 2020) e impuseram aos países e à sociedade o replanejamento do comportamento e atividades humanas e o cenário futuro ainda é incerto.

Desde a década de 1950, o surgimento de novas doenças zoonóticas foi identificado e várias epidemias foram relatadas em diversas partes do mundo (WERNECKE et al. 2020). Obviamente é importante ressaltar que o diagnóstico também é emergente,

6 https://covid19.who.int/ 
uma vez que neste período surgem as técnicas de microscopia eletrônica, os diagnósticos moleculares e técnicas genômicas que hoje permitem sequenciar e diferenciar espécies de microrganismos, como vírus. Esse cenário é o que Barrett e colaboradores (BARRETT et al., 1998) classificam como terceira transição epidemiológica, caracterizada pela emergência de novas doenças infecciosas, reemergência de antigas doenças e ainda, o surgimento de patógenos resistentes a antibióticos, associados, em sua maioria, aos processos de globalização acelerada, ao aumento da produção e consumo de proteína animal (OTTE e PICA-CIAMARRA, 2021).

Muitas epidemias estão relacionadas à perda da biodiversidade, o que favorece espécies oportunistas, incluindo parasitos. Apesar de serem agentes de doenças, os parasitos são a maioria das espécies existentes na Terra (FERREIRA, 1973; POULIN e MORAND, 2000), e são fundamentais para a evolução da vida e para a dinâmica de ecossistemas, auxiliando na regulação das populações de hospedeiros e vetores e manutenção do equilíbrio ecológico (WOOD e JOHNSON, 2015).

As zoonoses, responsáveis por cerca de $60 \%$ das infecções em humanos (JONES et al. 2008), não respeitam fronteiras políticas e causam impactos maiores nas populações vulneráveis e na produção de alimento. Como já alertado por estudiosos e pela Organização Mundial da Saúde ${ }^{7}$ (OMS), evidências concretas apontam endemismos e novas doenças associadas ao uso do solo pela agropecuária, desmatamento, exploração descontrolada dos recursos naturais, urbanização excessiva e fragmentação de áreas naturais e grandes empreendimentos (VASCONCELOS et al. 2001; WORLD BANK, 2010; KREUDER JOHNSON et al., 2015). Esses impactos mais agressivos nos países mega diversos apontam o Brasil como "hotspot" para o surgimento de novas pandemias (ALLEN et al., 2017).

O convívio com as zoonoses faz parte da história evolutiva humana e a transmissão de agentes etiológicos entre animal-humano-humano-animal foi e é facilitada pela exposição a vetores; a ingestão de carne de caça, sobretudo as cruas ou malcozidas; o contato direto com animais e plantas domesticadas que se iniciou há 10.000 anos; as conquistas de novos territórios e o leva e traz de animais, plantas e fômites (MCMICHAEL, 2004).

Talvez a pandemia mais famosa da antiguidade seja a peste negra, ou peste bubônica, responsável por dizimar cerca de $1 / 3$ da população europeia no Século XIV (UJVARI, 2008). Considerando o cenário da pandemia de peste no período medieval, pode-se também identificar padrões que a caracterizariam como um desastre ecológico. Mas, ainda que atualmente o tratamento para a peste bubônica seja acessível e eficaz, a existência de focos naturais ativos e o medo de novos surtos por variantes da Yersinia pestis resistentes aos antibióticos, faz com que a vigilância de cães, roedores e pulgas seja mantida no Brasil e em outros países ${ }^{8}$ (WORLD BANK, 2010).

A eliminação completa de um patógeno é algo quase impossível, já que implica na eliminação de ciclos naturais da doença, mantidos por hospedeiros animais há milhares de anos. A única doença humana mundialmente já erradicada é a varíola, assim

7 https://www.who.int/activities/prioritizing-diseases-for-research-and-development-in-emergency-contexts

8 https://www.sbmt.org.br/portal/peste-ameaca-silenciosa-e-problema-de-saude-publica-mundial/ 
declarada em 1980, após campanha de vacinação em massa. Ainda assim, a erradicação só foi possível porque os humanos são os únicos hospedeiros, embora a origem da varíola seja controversa, com análises moleculares que indicam que o vírus pode ter se originado nos camelos domesticados na África e Ásia, ou de roedores que poderiam ter transmitido o vírus aos camelos e destes ao homem. A primeira vacina da história foi desenvolvida utilizando-se o vírus da varíola de bovinos, após observações feitas em mulheres que ordenhavam vacas e que não desenvolviam a doença humana (RIEDEL, 2005). Cabe ressaltar que para a maioria das zoonoses não há vacinas disponíveis (OSTFELD, 2010) e que muitas das existentes precisam de ajustes constantes para combater as variantes que surgem ininterruptamente.

\section{A emergência de doenças como consequência da perda da biodi- versidade e de alterações ambientais}

O "efeito de diluição" que a biodiversidade promove sobre a transmissão de zoonoses, em especial, as transmitidas por vetores, talvez seja um de seus maiores benefícios aos humanos. Conceito cunhado a partir dos estudos da Doença de Lyme nos EUA, atualmente a zoonose de origem vetorial mais comum nesse país (CDC, 2021), a infecção é causada por bactérias do gênero Borrelia que é transmitida aos humanos pela picada de carrapatos infectados. Por anos, hospedeiros como os cervos e roedores foram considerados culpados pela disseminação da doença, por alimentarem os carrapatos em áreas próximas às residências humanas. Estudos mais aprofundados, realizados em fragmentos florestais de tamanhos distintos, revelaram que quanto maior o fragmento e a biodiversidade menor é a prevalência e transmissão da bactéria aos hospedeiros (OSTFELD e KEESING, 2000; ESTRADA-PEÑA et al., 2014), e, ainda, que predadores como o gambá (Didelphis virginiana) consomem milhares de carrapatos por ano e. por isso, auxiliam no controle da doença (KEESING et al., 2009). No Brasil, estudos revelam efeito semelhante no aumento da ocorrência da doença de Chagas na Amazônia e outros biomas, em decorrência da perda da riqueza de pequenos mamíferos (XAVIER et al. 2012).

$\mathrm{O}$ fogo tem se revelado importante agente da promoção da malária na Amazônia (HAHN et al. 2014) e incêndios florestais intensos na Ásia, potencializados pelo El Niño nos anos 1997-1998, determinaram o surgimento de surtos do vírus Nipah, causando a morte de 100 pessoas na Malásia e o abate de 1 milhão de porcos para conter a doença (KARESH et al., 2012). O surgimento do Nipah vírus em humanos e porcos se deu pela permanência da fumaça na atmosfera, que reduziu a floração e frutificação nas florestas nativas da Indonésia, forçando morcegos frugívoros dispersarem em busca de alimento nos pomares das fazendas na Malásia. Transmitido pela saliva e urina dos morcegos, o vírus Nipah infectou porcos que se alimentavam dos frutos contaminados caídos e urina no chão (EPSTEIN et al., 2006) e estes infectaram pessoas. Este episódio, traz alerta importante, para a vigilância de zoonoses no Brasil, pois não só os morcegos, se movem em busca de alimento e abrigo após os desastres, como incêndios, outros animais voadores ou não, com maior mobilidade, também 
se dispersam levando consigo agentes infecciosos causadores da raiva, malária, chicungunha, Oropouche, leishmanioses, doença de Chagas, febre amarela, entre outras doenças (BONILLA-ALDANA et al., 2019).

O estabelecimento de espécies exóticas invasoras favorecidas pela ausência de competidores e predadores naturais é hoje uma das maiores causas de doenças infecciosas no Brasil. Na verdade, o país importa doenças desde a sua colonização, cujos agentes infecciosos e vetores aqui se adaptam e se tornam endêmicos (BUENO et al. 2016). A febre amarela nas Américas é excelente exemplo. Após ser introduzida com Aedes aegypti no século XVI pelos portos marítimos e causar epidemias em grandes centros urbanos até 1942, o vírus amarílico se adaptou a dezenas de mosquitos brasileiros e passou a infectar primatas não humanos ( $\mathrm{PNH}$ ) nativos, estabelecendo-se no ciclo silvestre (FIGUEIREDO, 2019). Os PNH infectados pelo vírus também adoecem e morrem e o real impacto a essas populações ainda é desconhecido (CHAME et al. 2020). No sentido oposto ("spillback"), o herpes vírus HHV-1 humano, tem matado grupos de saguis (Callithrix spp.) nas áreas florestadas e urbanas, onde há interação com humanos (LONGA, 2011).

Vale destacar o efeito interativo entre distúrbios e doenças bem ilustrados pelos danos causados pelo fogo dos incêndios florestais nas sequóias vermelhas americanas (Sequoia sempervirens), que com as cascas queimadas se tornam susceptíveis ao protista Phytophthora ramorum, adoecem e se tornam mais vulneráveis a outros incêndios, causando ruptura na teia trófica que elas sustentam (METZ et al. 2013).

Efeitos análogos e de magnitude planetária, com consequências de rompimento das teias tróficas, são observados nos oceanos. O acúmulo de $\mathrm{CO} 2$ reduz o pH da água, processo conhecido como a acidificação dos oceanos, causando impacto no comportamento (ROSSI et al. 2016), na reprodução, maturação sexual, desenvolvimento e sobrevivência de crustáceos por interferir em processos metabólicos (MILLER et al., 2016), na fixação de carbonatos e na dissolução da carapaça desses animais, deixando-os frágeis e expostos à ação de predadores, raios ultravioletas, entre outros riscos (BEDNARŠEK et al., 2020). Outros impactos têm disso observados em equinodermos, moluscos e corais (BHADURY, 2015) e a expectativa de que os oceanos sejam a alternativa para a produção de alimento para a crescente população humana (COSTELLO et al. 2020) encontra-se em risco.

\section{Considerações}

Apesar da pandemia de Covid-19 ainda não ter sido controlada, especialistas já reportam o risco de emergência de novas zoonoses. Nesse contexto, a busca de dados de qualidade e ferramentas para antecipação e prevenção desses agravos é urgente. Entretanto, somadas a outras urgências e mazelas, a vigilância em saúde e o monitoramento da saúde de animais silvestres é um desafio. A Fiocruz, em sua missão de apoiar o Sistema Único de Saúde (SUS) e a conservação da biodiversidade vem desenvolvendo estratégias para auxiliar nestas dificuldades. Para isso, lançou em 2014, o Sistema 
de Informação em Saúde Silvestre - SISS-Geo, gratuito na Web e aparelhos móveis que garante o registro de imagens "off line" georreferenciadas e informações sobre saúde da fauna silvestre. Nascido dos preceitos da ciência cidadã, qualquer pessoa interessada pode auxiliar nesse monitoramento (CHAME et al., 2019). Alertas automáticos, gerados por algoritmos que avaliam fatores de risco de zoonoses pré-estabelecidos são distribuídos aos órgãos de vigilância em saúde nos três níveis de governo. A rapidez das informações permite economia e eficiência na organização da logística municipal para investigação e diagnóstico laboratorial, gerando resultados disponíveis para identificação de áreas prioritárias para controle e prevenção, como a vacinação e modelos de previsão de ocorrência de zoonoses destinados às políticas públicas de saúde (CHAME et al., 2020; BRASIL, 2021).

Considerando as características, os fatores promotores da origem e as consequências das doenças zoonóticas, tratá-las como desastres ecológicos, possibilitaria fortalecer a integração entre as ferramentas e ações da gestão de desastres, a vigilância em saúde e o monitoramento da biodiversidade. Além do mais, ações conjuntas, integradas e participativas são oportunas para o avanço na percepção e conscientização do risco destas emergências na sociedade, empresas e especialmente nos governos. A implementação de estratégias para alcance de qualquer iniciativa que busque a sustentabilidade e permanência da espécie humana no planeta deve ser conjugada, objetivando eficácia, eficiência, economia, equidade, justiça social, obrigatoriamente conservar a biodiversidade e ecossistemas saudáveis. O colapso ecológico não é uma hipótese e deve-se ter pressa. 


\section{Referências}

ALLEN, T. et al. Global hotspots and correlates of emerging zoonotic diseases. Nature Communications, 2017. 8, 1124, 2017. https://doi.org/10.1038/s41467-017-00923-8

BARRETT, R. et al. Emerging and Re-emerging infectious diseases: The Third Epidemiologic Transition. Annual Review of Anthropology, v. 27, p. 247-271, 1998.

BEDNARŠEK, N. et al. Exoskeleton dissolution with mechanoreceptor damage in larval Dungeness crab related to severity of present-day ocean acidification vertical gradients. Science of the Total Environment, v. 716, 2020.

BHADURY, P. Effects of ocean acidification on marine invertebrates-a review. Indian Journal of Geo-Marine Sciences, v. 44, n. 4, p. 454-464, 2015.

BONILLA-ALDANA, D. K. et al. Brazil burning! What is the potential impact of the Amazon wildfires on vector-borne and zoonotic emerging diseases? - A statement from an international expert meeting. Travel Medicine and Infectious Disease, v. 31, p. 101474, 2019.

BRASIL. Guia de Vigilância em Saúde [recurso eletrônico] / Ministério da Saúde, Secretaria de Vigilância em Saúde. Coordenação-Geral de Desenvolvimento da Epidemiologia em Serviços. - 5. ed. - Brasília, 2021. 1.126 https://bvsms.saude.gov.br/ bvs/publicacoes/guia_vigilancia_saude_5ed.pdf

BUENO, M. G. et al. Animals in the Zika Virus Life Cycle: What to Expect from Megadiverse Latin American Countries. PLOS Neglected Tropical Diseases, v. 10, n. 12, p. e0005073, 2016.

CDC. Lyme Disease. Disponível em: <https://www.cdc.gov/lyme/index.html>. Acesso em: 31 out. 2021.

CHAME, M. et al. Primates in SISS-Geo: potential contributions of mobile technology, health surveillance and citizen science to support species conservation in Brazil. v. 26, n. December, p. 80-89, 2020.

CHAME, M. et al. SISS-Geo: Leveraging Citizen Science to Monitor Wildlife Health Risks in Brazil. Journal of Healthcare Informatics Research, v. 3, n. 4, p. 414-440, 2019.

CORONESE, M. et al. Evidence for sharp increase in the economic damages of extreme natural disasters. Proceedings of the National Academy of Sciences, v. 116, n. 43, p. 21450-21455, 2019. 
COSTELLO, C. et al. The future of food from the sea. Nature, 2020. 588:7836, v. 588, n. 7836, p. 95-100, 19 ago. 2020.

Di GUARDO G. Future trajectories of SARS-CoV-2 in animals. Vet Rec. 2021 Jun;188(12):475. doi: 10.1002/vetr.663. PMID: 34143465 ; PMCID: PMC8441677

DOBSON, AP et al. Ecology and economics for pandemic prevention. Science, vol. 369, Issue 6502, pp. 379-381, 2020 DOI: 10.1126/science.abc3189

EPSTEIN, J. H. et al. Nipah virus: Impact, origins, and causes of emergence. Current Infectious Disease Reports, v. 8, n. 1, p. 59-65, 2006.

ESTRADA-PEÑA, A. et al. Effects of environmental change on zoonotic disease risk: An ecological primer. Trends in Parasitology, v. 30, n. 4, p. 205-214, 2014.

FERREIRA, L. F. O fenômeno parasitismo. Revista da Sociedade Brasileira de Medicina Tropical, v. 4, p. 261-277, 1973.

FIGUEIREDO, L. T. M. Human Urban Arboviruses Can Infect Wild Animals and Jump to Sylvatic Maintenance Cycles in South America. Frontiers in Cellular and Infection Microbiology, v. 9, p. 259, 2019.

GLADWELL M. The Tipping Point: How Little Things Can Make a Big Difference. New York, NY: Little Brown \& Company, 2000.

HAHN MB, et al. Influence of Deforestation, Logging, and Fire on Malaria in the Brazilian Amazon. PLoS ONE 9(1): e85725. 2014. https://doi.org/10.1371/journal. pone. 0085725

HULLAND, E et al. Increase in Reported Cholera Cases in Haiti Following Hurricane Matthew: An Interrupted Time Series Model. The American journal of tropical medicine and hygiene, 100(2), 368-373.2019 https://doi.org/10.4269/ajtmh.17-0964

IPCC. Contribution of Working Group I to the Sixth Assessment Report of the Intergovernmental Panel on Climate Change [Masson-Delmotte, V et al (eds.)]. 2021. Cambridge University Press. In Press. https://www.ipcc.ch/report/ar6/wg1/\#FullReport

JONES, K. E. et al. Global trends in emerging infectious diseases. Nature 451, 990993, 2008.

KARESH, W. B. et al. Ecology of zoonoses: natural and unnatural histories. v. 380, 2012. 
KEESING, F. et al. Hosts as ecological traps for the vector of Lyme disease. Proceedings of the Royal Society B: Biological Sciences, v. 276, n. 1675, p. 3911-3919, 2009.

KREUDER JOHNSON, C. et al. Spillover and pandemic properties of zoonotic viruses with high host plasticity. Scientific Reports, v. 5, 7 , 2015.

KREUDER JOHNSON, et al. Spillover and pandemic properties of zoonotic viruses with high host plasticity. Sci Rep 5, 14830 (2015). https://doi.org/10.1038/srep14830

LONGA, C. Human Herpesvirus 1 in Wild Marmosets, Brazil, 2008. Emerging Infectious Diseases, v. 17, n. 7, p. 1308-1310, jul. 2011.

MACIEL, G. F.; TONIATI, A. L.; FERREIRA, F. O. Cultura de gestão de riscos na mitigação de desastres 'naturais'. Revista Ibero Americana de Ciências Ambientais, v.12, n.2, p.671-686, 2021. DOI:10.6008/CBPC2179-6858.2021.002.0056

MCMICHAEL, A. J. Environmental and social influences on emerging infectious diseases: past, present and future. Philosophical Transactions of the Royal Society B: Biological Sciences, v. 359, n. 1447, p. 1049-1058, 2004.

METZ, M. R. et al. Unexpected redwood mortality from synergies between wildfire and an emerging infectious disease. Ecology, v. 94, n. 10, p. 2152-2159, out. 2013.

MILLER, J. J. et al. Exposure to low pH reduces survival and delays development in early life stages of Dungeness crab (Cancer magister). Marine Biology, v. 163, n. 5, p. $1-11,2016$.

OSTFELD, R. Lyme Disease: The Ecology of a Complex System. New York, NY: Oxford University Press, 2010.

OSTFELD, R. S.; KEESING, F. Biodiversity and disease risk: The case of Lyme disease. Conservation Biology, v. 14, n. 3, p. 722-728, 2000.

OTTE, J. \& PICA-CIAMARRA, U. Emerging infectious zoonotic diseases: The neglected role of food animals. One Health. 100323. Doi 10.1016/j.onehlt.2021.100323

PAUL, B. K. Natural Hazards and Disasters: From Avalanches and Climate Change to Water Spouts and Wildfires. Santa Barbara: ABC-CLIO, LLC, 2020.

POULIN, R., \& MORAND, S. The Diversity of Parasites. The Quarterly Review of Biology, 75(3), 277-293. 2000 http://www.jstor.org/stable/2665190) 
RIEDEL, S. Jenner and the History of Smallpox and Vaccination. v. 18, n. 1, p. 21-25, 2005.

ROSSI, T.; CONNELL, S. D.; NAGELKERKEN, I. Silent oceans: Ocean acidification impoverishes natural soundscapes by altering sound production of the world's noisiest marine invertebrate. Proceedings of the Royal Society B: Biological Sciences, v. 283, n. 1826, 2016.

UJVARI, S. C. A História da Humanidade Contada pelos Vírus. [s.1.] Contexto, 2008.

UNISDR 3rd United Nations World Conference. Sendai framework for disaster risk reduction 2015-2030. UNISDR Sendai. 2015 https://www.unisdr.org/we/coordinate/ sendai-framework.

VASCONCELOS, PFC et al. Gestão imprópria do ecossistema natural na Amazônia brasileira resulta na emergência e reemergência de arbovírus. Cad. Saúde Pública 17 (suppl), 2001. https://doi.org/10.1590/S0102-311X2001000700025

WERNECKE, B. et al. Preventing the next pandemic' - A 2020 UNEP Frontiers Series Report on zoonotic diseases with reflections for South Africa. South African Journal of Science, 116(7-8), 1-4.2020. https://dx.doi.org/10.17159/sajs.2020/8531

WOOD, C. L., \& JOHNSON, P. T. A world without parasites: exploring the hidden ecology of infection. Frontiers in ecology and the environment, 13(8), 425-434, 2015. https://doi.org/10.1890/140368

WORLD BANK. 2010. People, Pathogens, and Our Planet: Volume One - Towards a One Health Approach for Controlling Zoonotic Diseases. World Bank. (c) World Bank. https://openknowledge.worldbank.org/handle/10986/2844 License: CC BY 3.0 IGO."

XAVIER SCdC et al. Lower Richness of Small Wild Mammal Species and Chagas Disease Risk. PLoS Negl Trop Dis 6(5): e1647. 2012 https://doi.org/10.1371/journal. pntd.0001647 